\title{
PRODUÇÃO DE CONCRETO DE ALTO DESEMPENHO (CAD) COM ADIÇÃO DE PÓ DE PEDRA
}

\author{
PRODUCTION OF HIGH PERFORMANCE CONCRETE (HPC) WITH THE ADDITION \\ OF STONE POWDER
}

\section{RESUMO}

Vantagens como desformas rápidas, obtenção de peças estruturais com menores dimensões, agilidade na execução e aumento da vida útil da obra ocorrem devido à aplicação de concreto de alto desempenho (CAD) na construção civil. Caracterizado por possibilitar elevada resistência mecânica e durabilidade às estruturas, o emprego de novos materiais (como, por exemplo, adições minerais e aditivos químicos) são essenciais na conferência dessas propriedades ao concreto especial em questão. Dessa forma, o objetivo do estudo foi a elaboração de concretos de alto desempenho utilizando como adição o pó de pedra. Esse pó é resultante da moagem de rochas naturais em pedreira da região da PB e sua utilização em concretos visa, principalmente, evitar seu descarte e consequente geração de resíduos para o meio ambiente. Realizou-se a dosagem de dois traços referência (T1 e T2) desse concreto especial e, posteriormente, foi realizada a adição do pó em cada um, totalizando em 4 traços. Comparando-os entre si, foi possível constatar que o método de dosagem e execução do traço 1 (TI) obteve melhor desempenho, apresentando indícios de boa integridade no que diz respeito à durabilidade e elevada resistência mecânica (superior à 100 MPa aos 28 dias de idade). Além disso, observou-se também que o efeito "filler" gerado pela adição do pó de pedra no concreto colaborou de forma significativa para maiores ganhos de resistência mecânica do CAD.

Palavras-chave: Concreto de alto desempenho. Pó de pedra. Resistência mecânica. Durabilidade.

\footnotetext{
1 Graduada em Engenharia Civil pelo Centro Universitário de João Pessoa (UNIPÊ). E-mail: marcellasenab@gmail.com 2 Doutorando em Engenharia de Materiais pela Universidade Federal da Paraíba (UFPB). Docente do Centro Universitário de João Pessoa (UNIPÊ). E-mail: carlos.maviael@unipe.br

3 Graduanda em Engenharia Civil pelo Centro Universitário de João Pessoa (UNIPÊ). E-mail: rosane.ifpb@gmail.com 4 Graduando em Engenharia Civil pelo Centro Universitário de João Pessoa (UNIPÊ). E-mail: jailsonalves21@gmail.com 5 Graduando em Engenharia Civil pelo Centro Universitário de João Pessoa (UNIPÊ). E-mail: ewertonffoa@gmail.com 6 Mestranda em Engenharia Civil pela Universidade Federal de Pernambuco (UFPE).E-mail: marianapdantas@hotmail.com
} 


\section{ABSTRACT}

Advantages as quick desforms, acquisition of structural parts with smaller dimensions, agility in execution and increased lifetime of the construction occur due to high-performance concrete (HPC) application in the field of civil engineering. Characterized by enabling high mechanical resistance and durability to the structures, the use of new materials (as, for example, mineral additions and chemical additives) are essential in the conference of these properties to the special concrete in question. Thus, the objective of the study was the development of high performance concrete using as filler the stone powder. This powder is the result of the grinding of natural rocks in the quarry in the region of PB and their use in concretes aims, mainly, avoid discarding and consequent generation of waste for the environment. It was made the dosage of two traces as reference ( $\mathrm{Tl}$ and $\mathrm{T} 2$ ) of this special concrete and, afterwards, it was made the addition of stone powder in each one, totalizing in 4 traces. Comparing the traces with each other, it was possible to verify that the dosage method and execution of trace 1 (T1) achieved better performance, showing evidence of good integrity with regard to durability and high mechanical resistance (greater than $100 \mathrm{MPa}$ at 28 days of age). Besides that, it was also observed that the filler effect generated by the addition of stone powder in the concrete contributed significantly to higher mechanical strength gains of the HPC.

Keywords: High-performance concrete. Stone powder. Mechanical resistance. Durability.

\section{INTRODUÇÃO}

Progressos significativos no ramo do cálculo estrutural vêm permitindo que projetistas especifiquem estruturas cada vez mais arrojadas em concreto armado e protendido. Porém deve-se atentar que, muitas vezes, o concreto convencional pode não atender aos requisitos de projeto ou até mesmo existir opções melhores que remetam a uma relação técnica e econômica mais favorável (TUTIKIAN et al., 2011).

Não é novidade que, nos últimos anos, a tecnologia do concreto passou por aperfeiçoamentos devido a avanços nas técnicas de pesquisa e utilização de novos materiais. O surgimento desses materiais tornou possível uma expansão no uso dos concretos especiais, principalmente os concretos de alto desempenho (CAD) (ROSSIGNOLO, 2003).

Watanabe (2008) afirma que esse tipo de concreto é caracterizado por possuir elevada resistência mecânica aliada a uma maior durabilidade aos ataques de agentes agressivos provenientes do meio. Além disso, possui uma série de vantagens como: maior trabalhabilidade quando comparado ao concreto convencional, menor porosidade e permeabilidade, obtenção de pilares com 
menores dimensões, baixo custo com manutenção, maior rapidez de desforma e, consequentemente, aumento na produtividade da obra, etc.

Estudos afirmam que ao se aumentar a massa específica dos CAD - através de métodos de empacotamento - é mais fácil conferir as propriedades almejadas ao concreto especial. Esse método foi recentemente redescoberto como um parâmetro chave na obtenção de concretos de ultra/alto desempenho, tendo em vista o conceito de elevada densidade (CASTRO; PANDOLFELLI, 2009).

De acordo com Santos (2017) é notável que grande parte dos elementos construtivos são executados de forma convencional, esbanjando uma quantidade elevada de recursos naturais fazendo com que a racionalização e o melhor aproveitamento desses materiais se encontrem como alternativas ao consumo exagerado na construção civil.

Nas regiões onde sucede a atividade das indústrias mineradoras, especificamente no que diz respeito à fabricação de agregados, são estocados grandes volumes de material considerado como resíduo do processo de britagem de rochas: o pó de pedra. Várias pesquisas vêm sendo realizadas nesse âmbito, já que sua utilização pode proporcionar benefícios para as empresas mineradoras, uma vez que apresentarão maior lucratividade decorrente da comercialização de um produto proveniente de rejeito que não agrega valor ao processo (SOUZA et al., 2016).

Campos (2015) ainda sugere a utilização desse material visando princípios de sustentabilidade, como diminuição de resíduos e preservação de mananciais, além dos benefícios que o pó de pedra virá a proporcionar quando aplicado em concretos, como, por exemplo, durabilidade das estruturas. Dessa forma, o presente estudo foi desenvolvido visando melhorar as propriedades dos CAD através da adição do pó de pedra em sua composição.

\section{OBJETIVOS}

\section{GERAL}

Produção de concreto de alto desempenho (CAD) com adição de pó de pedra proveniente de pedreira da região da PB.

\section{ESPECÍFICOS}

- Realizar uma análise comparativa dos traços dosados sem e com adição do pó de pedra;

- Realizar ensaios que evidenciem questões voltadas à durabilidade e resistência mecânica dos concretos; 


\title{
REVISÃO BIBLIOGRÁFICA
}

\section{CONCRETO}

De acordo com Mehta e Monteiro (2008) alguns fatores foram responsáveis pelo grande sucesso do concreto como material de construção. Por exemplo, sua excelente resistência à ação da água (contrariamente ao aço e madeira), sua consistência plástica apresentar capacidade de adequação em tamanhos e formas variadas e, também, a vasta disponibilidade de seus materiais constituintes (cimento, agregados e água) aliados ao seu baixo custo se destacam como vantagens que fizeram do concreto o material aglomerante mais consumido no mundo para a construção civil.

Porém, nas últimas décadas, esse elemento passou por grandes avanços em virtude de dois fatores principais: o aperfeiçoamento de métodos e equipamentos voltados à tecnologia do concreto e o progresso no ramo dos novos materiais, enfatizando o surgimento das adições minerais e dos aditivos redutores de água (ROSSIGNOLO, 2009).

Decorrente disso, Neville (2016) destaca o aparecimento dos concretos especiais, sendo que o termo "especial" não significa que sejam incomuns. Na verdade, essa expressão se refere às características intrínsecas que são almejadas nesse tipo de concreto em determinadas situações. O concreto de baixa densidade, por exemplo, é um tipo de concreto especial que se utiliza novos materiais (agregado leve) para conferência das características desejadas, como redução no peso estrutural, melhoria no conforto térmico e acústico, maior resistência ao fogo, etc.

\section{CONCRETO DE ALTO DESEMPENHO (CAD)}

Segundo Watanabe (2008), é possível afirmar que:

\begin{abstract}
"Estudos experimentais comprovaram que a microestrutura e as propriedades do concreto com resistência acima de $40 \mathrm{MPa}$ são consideravelmente diferentes das encontradas nos concretos convencionais. Como a prática atual de dimensionamento de estruturas ainda está fundamentada em experimentos realizados com concretos convencionais, é preferível manter os concretos com resistências acima de $40 \mathrm{MPa}$ em uma classe diferenciada, de maneira a alertar o projetista da necessidade de ajustes nas equações existentes." (WATANABE, 2008).
\end{abstract}

É quase impossível, na prática, conseguir CAD sem a utilização das adições minerais e aditivos químicos, especialmente nas faixas de resistência acima de 40 MPa. O CAD em geral tem como característica essencial a baixa relação água/ cimento, o que exige a utilização de aditivos superplastificantes, proporcionando trabalhabilidade ao concreto (MEHTA e MONTEIRO, 1994). Além disso, é em virtude 
desse reduzido fator a/c que se obtém elevada resistência mecânica e durabilidade, características que diferenciam os CAD dos concretos convencionais.

Segundo Aïtcin (2000), os concretos de alto desempenho são classificados de acordo com a Tabela 1.

Tabela 1: Classes de Concreto de Alto Desempenho.

\section{Classe do concreto Resistência à compressão (MPa)}

\begin{tabular}{cc} 
Classe I & $50-75$ \\
\hline Classe II & $75-100$ \\
\hline Classe III & $100-125$ \\
\hline Classe IV & $125-150$ \\
\hline Classe V & $>150$ \\
\hline
\end{tabular}

Fonte: Adaptado de Aïtcin, 2000.

\section{FATOR DE EMPACOTAMENTO}

Conforme Monson et al. (2016) o preenchimento de espaços entre grãos pode ser definido como empacotamento de partículas, onde a junção desses grãos de diferentes tamanhos se combinam e os vazios gerados pelas partículas maiores são preenchidos pelas menores e assim por diante. $O$ aprimoramento da dosagem em função do empacotamento propicia redução na porosidade e consequente diminuição da pasta de cimento.

Os estudos referentes a esse método são antigos, o primeiro datando em 1892 em que Féret publicou sua pesquisa sobre empacotamento de partículas, onde a equação apresentada mostrou que quanto maior a densidade de empacotamento menor seria a porosidade resultando em maiores ganhos de resistência mecânica do concreto (AIQIN et al., 1997; AIQIN et al., 1999; DE LARRARD e SEDRAN, 1994). Com essa descoberta, vários outros modelos foram desenvolvidos e aperfeiçoados. Nesse contexto, o Modelo de Alfred se encontra como um melhoramento de métodos anteriores - Modelo de Furnas e Modelo de Andreassen -, conforme é mostrado na Equação 1.

$$
\operatorname{CPTF}(\%)=100 *\left(\frac{D^{q}}{D_{L}^{q}}-\frac{D_{S}^{q}}{D_{S}^{q}}\right)
$$

Onde:

CPTF $=$ porcentagem volumétrica das partículas menores que o diâmetro $D_{p}$;

$\mathrm{D}_{\mathrm{s}}=$ diâmetro da menor partícula;

$D_{L}=$ diâmetro da maior partícula;

$q=$ coeficiente de distribuição. 
Tanto para o Modelo de Andreassen como para o Modelo de Alfred é necessário adotar um valor para o coeficiente de distribuição (q), sendo o valor $\mathrm{q}=0,37$ o que alcançaria o máximo empacotamento de partículas, de acordo com Funk e Dinger (1992) apud Oliveira et al. (2000).

\section{PÓ DE PEDRA}

De acordo com John e Agopyan (2003) a construção civil se firma como um dos principais agentes de degradação ambiental em virtude da elevada emissão de polventes, extração de recursos naturais - visando suprir as necessidades de produção - e pela elevada geração de resíduos. Frente ao exposto, a reciclagem se encontra como uma boa alternativa. Pera (1996) afirma que a proteção do solo e da água, restrição na produção de perdas e reutilização de materiais são pontos importantes para o desenvolvimento sustentável.

Sendo resultante da moagem de rochas em pedreiras, a areia de brita (ou pó de pedra) é oriunda do peneiramento de britas à seco cuja granulometria está compreendida entre 4,75-0,075 mm. Abaixo desse valor mínimo, temos o que é conhecido como "finos de pedreira", provenientes de processos de obtenção por sistemas de aeração (ventilação e exaustão) ou por vias de umidade (bacias de decantação). Neste último, o material gerado faz com que o assoreamento desses volumes d'água se torne desfavorável ao processo produtivo (CUCHIERATO, 2000).

Santos et al. (2018) afirma que, por estar depositado ao ar livre e em grandes volumes, o pó de pedra acaba se transformando num polvente ambiental direto, contaminando a água, o solo, o ar, provocando doenças respiratórias, entre outros impactos diretos. Além disso, Duarte (2013) destaca que o pó de pedra representa de 15 a $20 \%$ da produção de uma exploração de britagem.

Quanto da aplicação desse material no concreto, Silva e Silva (2012) salientam que propicia qualidade e maior segurança nas construções, fatores fundamentais no setor da engenharia civil. Já Menossi (2004) afirma que a trabalhabilidade e resistência à compressão são influenciadas pelo formato que os grãos possuem. $O$ pó de pedra também melhora essas duas características, pois possuem partículas equidimensionais (ALMEIDA e SAMPAIO, 2002).

Outras pesquisas destacam que o pó de pedra propicia um pequeno aumento de custo devido à ocasional necessidade de acréscimo cimentício, porém já existem estudos que comprovam sua viabilidade técnica como compósito (SOARES et al., 1996; SOARES e MENDES, 1999; MENDES, 1999). Ainda, Terra (2000) afirma que devido à disposição de controle tecnológico das concreteiras, as mesmas conseguem adquirir um bom aproveitamento do material, podendo proporcionar, ao mesmo tempo, baixo consumo de cimento, boa qualidade e trabalhabilidade do concreto. 


\section{PROGRAMA EXPERIMENTAL}

Por possuir natureza experimental e exploratória, a pesquisa foi dividida em etapas. Inicialmente, foram feitas pesquisas bibliográficas acerca do assunto e, tendo posse de algumas referências, foi feita a caracterização dos materiais para posterior dosagem dos traços referência e com adição do pó de pedra. Decorrente disso foi feita a confecção dos concretos e realização de ensaios previstos para análise de suas propriedades. Todo o processo experimental ocorreu no Complexo Laboratorial de Engenharia do Centro Universitário de João Pessoa - UNIPÊ.

\section{CARACTERIZAÇÃO DOS MATERIAIS}

\section{Cimento}

O aglomerante usado para essa pesquisa foi O cimento CPV ARI, comercializado pela Brennand Cimentos. Conforme ensaio previsto na ABNT NM 23:2000, foi possível obter um valor médio de $2,98 \mathrm{~g} / \mathrm{cm}^{3}$ para sua massa específica.

\section{Agregados}

Osagregados miúdos (areia) e graúdos (brita) utilizadosforam disponibilizados pela Instituição. Ensaios de massa específica, massa unitária e granulometrias foram realizados no material para uma melhor dosagem do traço, conforme é ilustrado na Tabela 2.

Tabela 2: Ensaios de caracterização dos agregados utilizados.

\begin{tabular}{|c|c|c|c|c|c|c|c|c|c|}
\hline \multicolumn{10}{|c|}{ ENSAIO GRANULOMÉTRICO (ABNT NM 248:2003) } \\
\hline \multirow{8}{*}{$\frac{\overleftarrow{u}}{\frac{\mathbb{\alpha}}{\alpha}}$} & $\begin{array}{c}\text { Abertura } \\
\text { das peneiras } \\
(\mathrm{mm})\end{array}$ & Peso retido (g) & $\begin{array}{l}\text { \% reti- } \\
\text { da }\end{array}$ & $\begin{array}{l}\text { \% retida } \\
\text { acumulada }\end{array}$ & \multirow{8}{*}{$\underset{\frac{\mathbb{N}}{\mathrm{N}}}{\mathbb{E}}$} & $\begin{array}{l}\text { Abertura } \\
\text { das penei- } \\
\text { ras (mm) }\end{array}$ & $\begin{array}{l}\text { Peso } \\
\text { retido } \\
\text { (g) }\end{array}$ & $\%$ retida & $\begin{array}{l}\text { \% retida } \\
\text { acumulada }\end{array}$ \\
\hline & 4,75 & 0 & 0 & 0 & & 25 & 0 & 0 & 0 \\
\hline & 2,36 & 16,2 & 1,62 & 1,62 & & 19 & 0 & 0 & 0 \\
\hline & 1,18 & 69,1 & 6,91 & 8,53 & & 12,5 & 0 & 0 & 0 \\
\hline & 0,6 & 159,2 & 15,92 & 24,45 & & 9,5 & 116,7 & 11,69 & 11,69 \\
\hline & 0,3 & 268,3 & 26,83 & 51,28 & & 6,3 & 542 & 54,29 & 65,98 \\
\hline & 0,15 & 291,8 & 29,18 & 80,46 & & 4,75 & 194,6 & 19,5 & 85,48 \\
\hline & Fundo & 195,4 & 19,54 & 100 & & 2,36 & 145 & 14,52 & 100 \\
\hline \multicolumn{4}{|c|}{ Diâmetro máximo característico (mm) } & 2,36 & \multicolumn{4}{|c|}{$\begin{array}{l}\text { Diâmetro máximo característico } \\
\qquad(\mathrm{mm})\end{array}$} & 12,5 \\
\hline \multicolumn{4}{|c|}{ Módulo de finura } & 1,66 & \multicolumn{4}{|c|}{ Módulo de finura } & 1,86 \\
\hline \multicolumn{4}{|c|}{$\begin{array}{c}\text { Massa específica aparente seca }(\mathrm{g} / \mathrm{mL} \text { ) } \\
\text { (ABNT NM 53:2009) }\end{array}$} & 2,65 & \multicolumn{4}{|c|}{$\begin{array}{l}\text { Massa específica aparente seca } \\
(\mathrm{g} / \mathrm{mL})(\text { (ABNT NM 53:2009) }\end{array}$} & 2,63 \\
\hline \multicolumn{4}{|c|}{ Massa unitária $\left(\mathrm{g} / \mathrm{cm}^{3}\right)$ (ABNT NM 45:2006) } & 1,44 & \multicolumn{4}{|c|}{$\begin{array}{l}\text { Massa unitária }\left(\mathrm{g} / \mathrm{cm}^{3}\right) \text { (ABNT NM } \\
45: 2006)\end{array}$} & 1,43 \\
\hline
\end{tabular}

Fonte: Autora, 2018. 


\section{Pó de pedra}

Geralmente utilizado em substituição ao agregado miúdo, esse material (Figura 1) foi obtido em pedreira da região da PB. Objetivando uma diferente utilização nesse estudo (adição ao concreto), ele foi caraterizado também quanto à massa específica, massa unitária e granulometrias, mas com resultados dispostos separadamente, conforme é ilustrado na Tabela 3.

Figura 1: Pó de pedra utilizado no estudo.

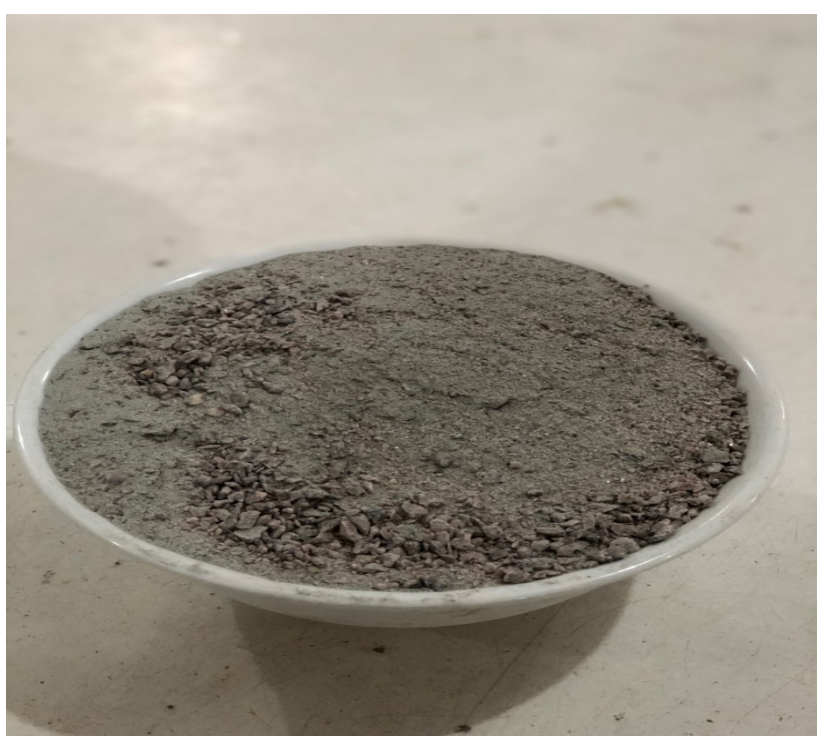

Fonte: Autora, 2018.

Tabela 3: Ensaios de caracterização do pó de pedra.

\begin{tabular}{|c|c|c|c|c|}
\hline \multicolumn{5}{|c|}{ ENSAIO GRANULOMÉTRICO (ABNT NM 248:2003) } \\
\hline \multirow{8}{*}{ 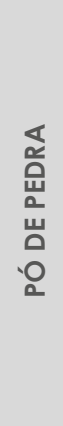 } & $\begin{array}{l}\text { Abertura das } \\
\text { peneiras }(\mathrm{mm})\end{array}$ & Peso retido $(g)$ & $\%$ retida & $\%$ retida acumulada \\
\hline & 4,75 & 0 & 0 & 0 \\
\hline & 2,36 & 163,2 & 16,32 & 16,32 \\
\hline & 1,18 & 165,7 & 16,57 & 32,89 \\
\hline & 0,6 & 151,4 & 15,14 & 48,03 \\
\hline & 0,3 & 142,3 & 14,23 & 62,26 \\
\hline & 0,15 & 224,2 & 22,42 & 84,68 \\
\hline & Fundo & 153,2 & 15,32 & 100 \\
\hline \multicolumn{4}{|c|}{ Diâmetro máximo característico (mm) } & 4,75 \\
\hline \multicolumn{4}{|c|}{ Módulo de finura } & 2,44 \\
\hline \multicolumn{4}{|c|}{ Massa específica aparente seca (g/mL) (ABNT NM 53:2009) } & 2,75 \\
\hline \multicolumn{4}{|c|}{ Massa unitária $\left(\mathrm{g} / \mathrm{cm}^{3}\right)$ (ABNT NM 45:2006) } & 1,68 \\
\hline
\end{tabular}

Fonte: Autora, 2018. 


\section{Sílica ativa}

Adicionada com o intuito de melhorar as propriedades de trabalhabilidade, resistência à fissuração térmica, ao ataque de sulfatos e à expansão álcali-agregado, a sílica ativa (Figura 2) utilizada na pesquisa foi fornecida pela empresa Tecnosil apresentando valor de massa específica informada em sua ficha de especificação técnica, sendo igual a $2,22 \mathrm{~g} / \mathrm{cm}^{3}$ e apresentando teor de $\mathrm{SiO}_{2}>90 \%$.

Figura 2: Sílica ativa utilizada na pesquisa.

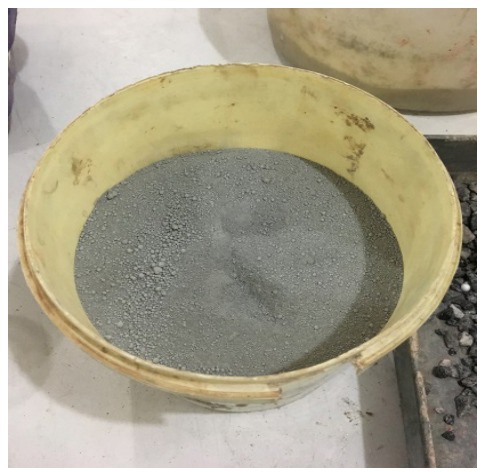

Fonte: Autora, 2018.

\section{Aditivo}

Foi utilizado o aditivo ADVA CAST 525 fornecido pela empresa GCP Applied Technologies, ilustrado na Figura 3, com o intuito de obter menores valores a/c e possuir trabalhabilidade adequada para moldagem dos CAD.

Figura 3: Aditivo utilizado na confecção dos concretos.

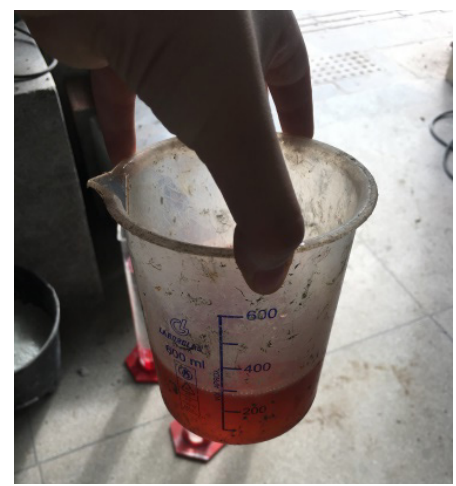

Fonte: Autora, 2018.

\section{DOSAGEM DOS CONCRETOS}

Após o processo de caracterização dos materiais, foi possível realizar a dosagem dos traços 1 e 2 através do método $\mathrm{ACl}$ (American Concrete Institute). 
Ainda, após a realização de testes preliminares, esses traços passaram por ajustes visando um melhor desempenho. A Tabela 4 ilustra as dosagens realizadas sem e com adição de pó de pedra.

Tabela 4: Dosagem unitária dos concretos.

\begin{tabular}{ccccc}
\hline Composição dos materiais utilizados & T1 & T1PP & T2 & T2PP \\
Cimento & 1 & 1 & 1 & 1 \\
Areia & 0,24 & 0,24 & 0,36 & 0,36 \\
Brita & 0,71 & 0,71 & 1,03 & 1,03 \\
Pó de pedra & - & 0,27 & - & 0,27 \\
Sílica ativa & 0,12 & 0,08 & 0,12 & 0,085 \\
Aditivo & 0,025 & 0,025 & 0,025 & 0,025 \\
a/c & 0,17 & 0,18 & 0,2 & 0,22 \\
\hline
\end{tabular}

Fonte: Autora, 2018.

Já que sua utilização foi objetivada como adição, o pó de pedra passou por um processo de peneiramento (Figura 4) até obter-se a quantidade necessária para execução dos traços. Dessa forma, conforme a realização de experimentações anteriores, foi optado pela utilização do material retido na peneira de malha 100.

Figura 4: Processo de peneiramento do pó de pedra.

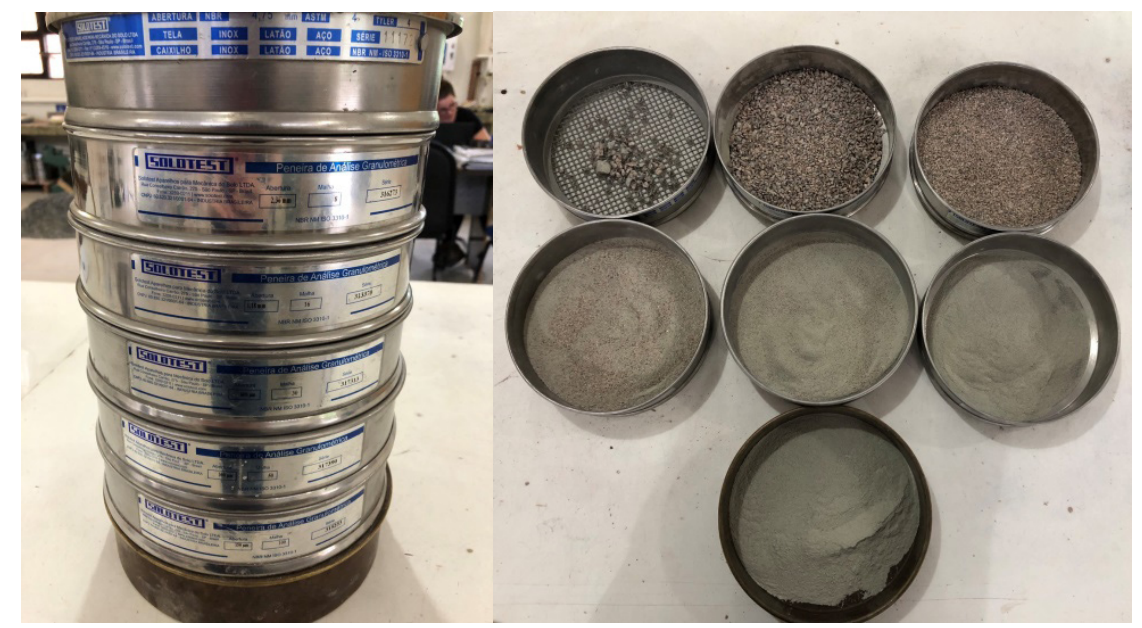

Fonte: Autora, 2018.

Além disso, objetivando um maior ganho de resistência, foi optado por uma maior densificação dos concretos ao realizar o empacotamento dos agregados. Os teores de empacotamento para cada um são ilustrados pela Tabela 5, onde foram obtidos através do Modelo de Alfred (Equação 1). 
Tabela 5: Teores de empacotamento utilizado nos agregados.

\begin{tabular}{|c|c|c|c|}
\hline \multirow{4}{*}{ 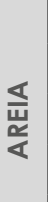 } & Abertura das peneiras $(\mathrm{mm})$ & Passante (\%) & Acumulado (\%) \\
\hline & 1,2 & 100 & 0 \\
\hline & 0,6 & 57,85 & 42,15 \\
\hline & 0,3 & 25,24 & 32,61 \\
\hline \multirow{7}{*}{$\underset{\frac{\mathbb{N}}{\infty}}{\mathbb{E}}$} & 0,15 & 0 & 25,24 \\
\hline & Abertura das peneiras $(\mathrm{mm})$ & Passante (\%) & Acumulado (\%) \\
\hline & 19 & 100 & 0 \\
\hline & 12,5 & 64,23 & 35,77 \\
\hline & 9,5 & 43,62 & 20,61 \\
\hline & 6,3 & 16,43 & 27,19 \\
\hline & 4,75 & 0 & 16,43 \\
\hline
\end{tabular}

Fonte: Autora, 2018.

\section{PRODUÇÃO DOS CONCRETOS}

A execução dos traços se deu através de betoneira da marca CSM e com capacidade de 130 litros, conforme ilustra a Figura 5. Primeiramente, foram adicionados os materiais secos (cimento, agregados, sílica e pó de pedra) para uma pré-homogeneização; posteriormente, foi sendo adicionada a água e o aditivo diluído na mesma, sempre alternando, até que o concreto atingisse consistência adequada para moldagem e atentando-se para obtenção de um menor a/c possível, visando às características almejadas nos CAD.

Figura 5: Betoneira utilizada na produção dos CAD.

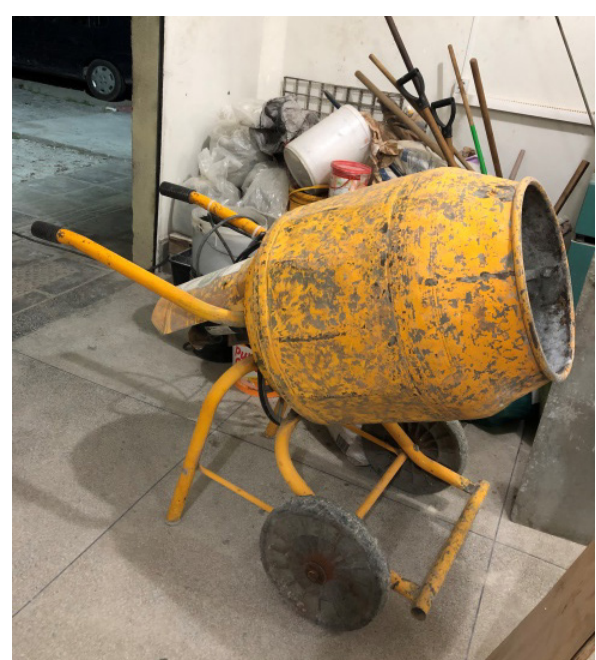

Fonte: Autora, 2018.

Após execução dos traços, foram moldados 9 corpos de prova cilíndricos de dimensões $10 \times 20 \mathrm{~cm}$ para cada um, totalizando em 36 cilindros. Estes se mantiveram à temperatura ambiente por 24 horas para então serem submetidos ao processo 
de cura, que foi do tipo úmida; os cilindros permaneceram imersos em tanques de água à temperatura de $23^{\circ} \mathrm{C}$ até as idades de rompimento: 3,7 e 28 dias.

\section{ENSAIOS REALIZADOS NOS CONCRETOS}

\section{Resistência à compressão axial e massa específica}

Os corpos de prova moldados foram ensaios quanto à resistência à compressão axial segundo os preceitos da NBR 5739 (ABNT, 2007) nas idades estabelecidas neste trabalho (3, 7 e 28 dias).

\section{Carbonatação}

Visando analisar as propriedades dos concretos produzidos quanto à carbonatação, foi realizada a aspersão de fenolftaleína nos corpos de prova rompidos, sabendo que essa característica é um dos principais indicadores que comprometem a durabilidade em estruturas. Os concretos foram ensaiados ao atingirem 28 dias de idade.

\section{RESULTADOS E DISCUSSÃO}

Os concretos foram ensaiados quanto à resistência à compressão, de acordo com as indicações da ABNT NBR 5739 (2007), ao atingirem as idades estabelecidas nessa pesquisa. A resistência final foi obtida pela média aritmética de 3 corpos de prova rompidos em cada idade, e através dos resultados obtidos, foi possível a montagem da Tabela 6.

Tabela 6: Valores de resistência dos concretos.

\begin{tabular}{|c|c|c|c|c|}
\hline \multicolumn{5}{|c|}{ T1 } \\
\hline Idade de rompimento (Dias) & $\mathrm{CP} 1(\mathrm{MPa})$ & $\mathrm{CP} 2(\mathrm{MPa})$ & CP3 (MPa) & MÉDIA (MPa) \\
\hline 3 & 86,88 & 79,84 & 78,89 & 81,87 \\
\hline 7 & 86,24 & 89,37 & 85,72 & 87,11 \\
\hline 28 & 100,53 & 105,9 & 103,62 & 103,35 \\
\hline \multicolumn{5}{|c|}{ TIPP } \\
\hline Idade de rompimento (Dias) & CP1 (MPa) & $\mathrm{CP2}(\mathrm{MPa})$ & CP3 (MPa) & MÉDIA (MPa) \\
\hline 3 & 88,6 & 91,35 & 90,05 & 90 \\
\hline 7 & 97,74 & 94,66 & 94,7 & 95,7 \\
\hline 28 & 112,88 & 113,84 & 111,98 & 112,9 \\
\hline \multicolumn{5}{|c|}{$\mathrm{T2}$} \\
\hline Idade de rompimento (Dias) & $\mathrm{CP} 1(\mathrm{MPa})$ & $\mathrm{CP} 2(\mathrm{MPa})$ & CP3 (MPa) & MÉDIA (MPa) \\
\hline 3 & 73 & 75,04 & 74,92 & 74,32 \\
\hline 7 & 80,82 & 81,14 & 79,72 & 80,56 \\
\hline 28 & 98,25 & 95,13 & 96,75 & 96,71 \\
\hline
\end{tabular}


T2PP

\begin{tabular}{ccccc}
\hline Idade de rompimento (Dias) & $\mathbf{C P 1}(\mathbf{M P a})$ & $\mathbf{C P 2}(\mathbf{M P a})$ & $\mathbf{C P 3}(\mathbf{M P a})$ & MÉDIA (MPa) \\
\hline 3 & 80,24 & 84,04 & 84 & $\mathbf{8 2 , 7 6}$ \\
\hline 7 & 88,25 & 90,33 & 88,12 & $\mathbf{8 9 , 9}$ \\
\hline 28 & 103,12 & 105,15 & 107,03 & $\mathbf{1 0 5 , \mathbf { 1 }}$ \\
\hline
\end{tabular}

Fonte: Autora, 2018.

Frente ao exposto, foi possível observar que o TIPP obteve maiores valores de resistência em todas as idades na qual foi ensaiado em relação aos demais traços, enfatizando que o Tl (traço referência) foi o que obteve o melhor método de dosagem e, ao utilizar o pó de pedra como adição (além da sílica ativa), foi possível obter um traço (TIPP) de maior resistência ainda, como é evidenciado no Gráfico 1.

Gráfico 1: Resistência à compressão média de cada traço em suas respectivas idades.

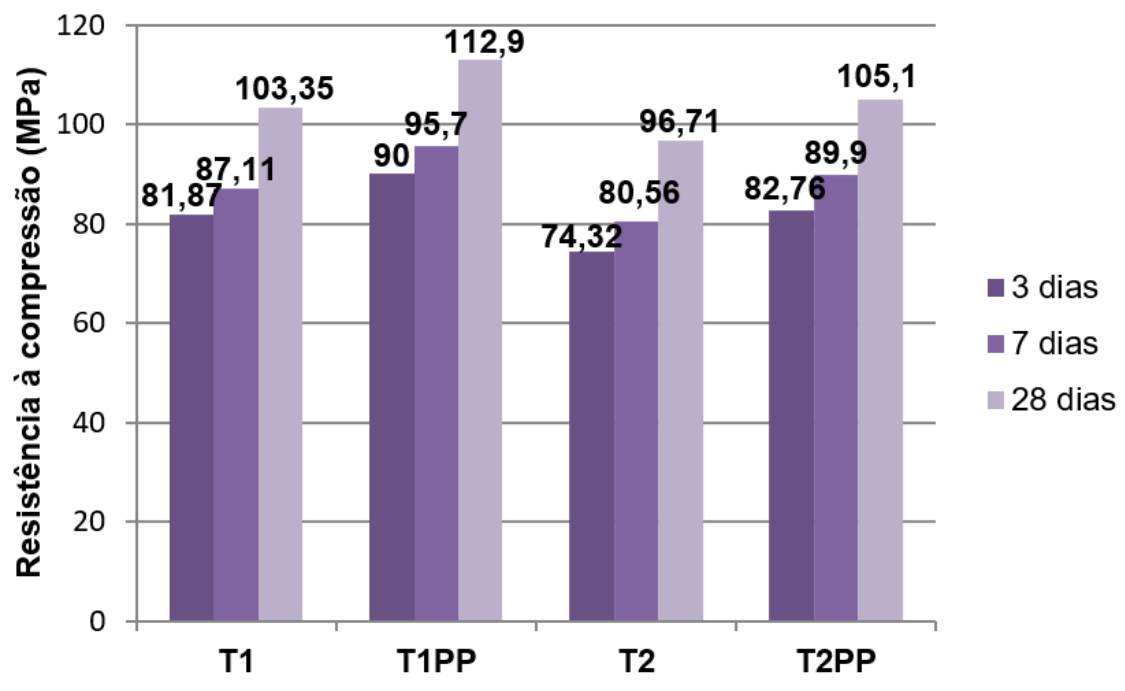

Fonte: Autora, 2018.

Além disso, para todos os traços, obteve-se relações água/cimento de até 0,22 . Visto que a porcentagem de aditivo permaneceu a mesma para todas as dosagens, essa relação aumentou à medida que se incorporava materiais finos, como o pó de pedra. O Gráfico 2 ilustra que, em relação aos traços referência (T1 e T2), os concretos com adição de pó de pedra (T1PP e T2PP) tiveram um maior a/c. 
Gráfico 2: Resistência à compressão X Relação a/c.

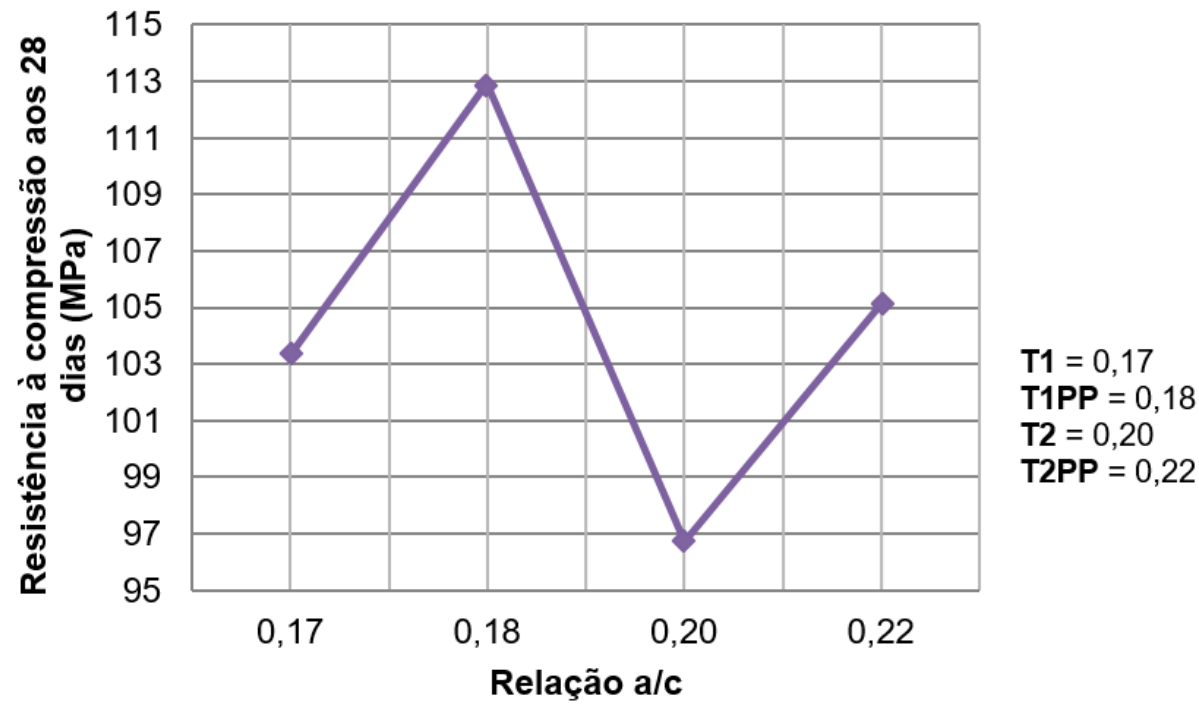

Fonte: Autora, 2018.

Ainda, de acordo com Gráfico 2, é observado que os concretos com a adição proposta (T1PP eT2PP) obtiveram maiores ganhos de resistência mecânica, mesmo com um a/c maior em relação aos seus respectivos traços referência. Isso ocorreu devido ao efeito de preenchimento que o pó de pedra proporcionou aos concretos produzidos, agindo como "fíller" e diminuindo os vazios, influenciando diretamente na resistência mecânica.

Já objetivando analisar características quanto à durabilidade, todos os traços foram ensaiados ao atingirem a idade de 28 dias no que diz respeito à carbonatação. Foi realizada uma simples aspersão de solução à base de fenolftaleína - por ser conhecido como um bom indicador de corrosão - sobre os corpos de prova após o ensaio de resistência à compressão. Assim, foi possível observar que todos os traços confeccionados apresentaram índices de $\mathrm{pH}$ aceitáveis para concreto de cobrimento, conforme é ilustrado na Figura 6, onde a cor arroxeada indica que não houve carbonatação. 
Figura 6: Da esquerda pra direita: T1, T1PP, T2 e T2PP.

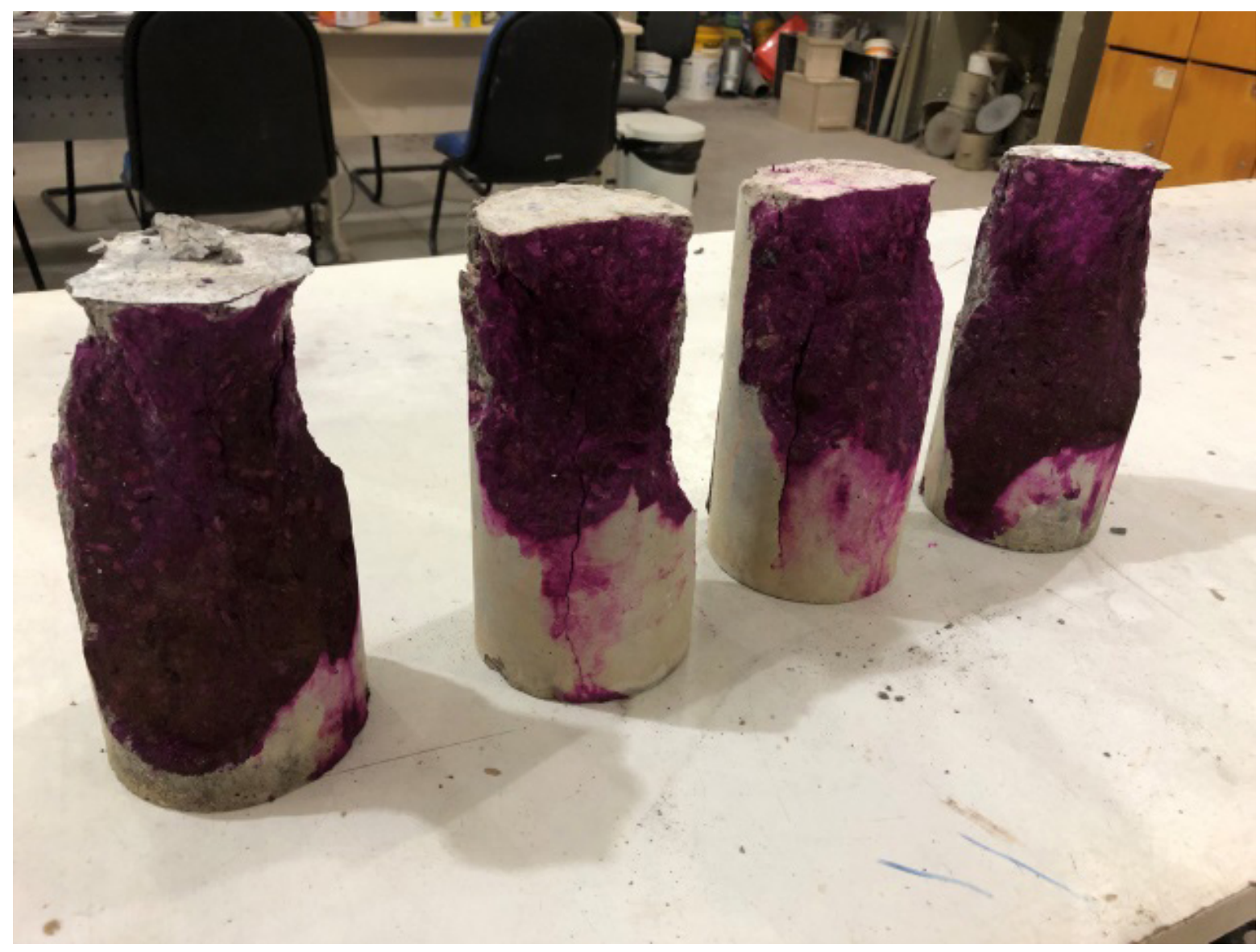

Fonte: Autora, 2018.

\section{CONSIDERAÇÕES FINAIS}

Perante a metodologia utilizada e resultados expostos, é possível concluir que o programa experimental se mostrou eficiente frente aos objetivos propostos ao produzir concretos de alto desempenho (CAD) com adição de pó de pedra.

Osmelhoresresultados quanto à resistênciaà compressão foram nos concretos que possuíram esse material como adição, tendo o T1PP e T2PP apresentado, aos 28 dias, valores de resistência igual a 112,9 MPa e 105,1 MPa, respectivamente.

Porém, o método de dosagem do T1 se mostrou mais eficiente que o T2 ao apresentar valores de resistência maiores nos traços com e sem adição do pó de pedra, para todas as idades ensaiadas. Além disso, pode-se enfatizar a importância do método de empacotamento utilizado nos agregados da pesquisa para os ganhos de resistência obtidos.

Frente ao exposto, os traços de CAD confeccionados apresentaram altos valores de resistência devido à preocupação quanto à ausência de vazios (utilizando o pó de pedra retido na malha 100 em conjunto à sílica ativa, como adições) e maior densificação dos concretos (ao optar por empacotar os agregados miúdos e graúdos). 
Já em relação à durabilidade, apesar de serem necessários estudos mais aprofundados para garantir tais questões, o ensaio de carbonatação indicou boa integridade por parte dos concretos.

Sendo assim, diante das informações expostas, é possível verificar uma funcionalidade na adição de granulometrias menores de pó de pedra na confecção de concretos de alta resistência (CAR) e alto desempenho (CAD) para maiores ganhos de resistência mecânica.

\section{REFERÊNCIAS}

AIQIN, W.; CHENGZHI, Z.; NINGSHENG, Z. Study of the influence of the particle size distribution on the properties of cement. Cement Concrete Research, 1997.

AIQIN, W.; CHENGZHI, Z.; NINGSHENG, Z. The theoretic analysis of the influence of the particle size distribution of cement system on the property of cement. Cement Concrete Research, 1999.

AïTCIN, Pierre-Claude. Concreto de alto-desempenho. $1^{a}$ ed. São Paulo: PINI, 2000.

ALMEIDA, S. L. M.; SAMPAIO, J. A. Obtenção de areia artificial com base em finos de pedreiras. Revista Areia \& Brita, out/dez de 2002.

ASSOCIAÇÃO BRASILEIRA DE NORMAS TÉCNICAS (ABNT). NBR 5739: Concreto - Ensaio a compressão de corpos-de-prova cilíndricos. Rio de Janeiro, 2007.

ASSOCIAÇÃO BRASILEIRA DE NORMAS TÉCNICAS (ABNT). NBR NM 23: Cimento portland e outros materiais em pó - Determinação da massa específica. Rio de Janeiro, 2000.

ASSOCIAÇÃO BRASILEIRA DE NORMAS TÉCNICAS (ABNT). NBR NM 248: Agregados Determinação da composição granulométrica. Rio de Janeiro, 2003.

ASSOCIAÇÃO BRASILEIRA DE NORMAS TÉCNICAS (ABNT). NBR NM 45: Agregados Determinação da massa unitária e do volume de vazios. Rio de Janeiro, 2006.

ASSOCIAÇÃO BRASILEIRA DE NORMAS TÉCNICAS (ABNT). NBR NM 53: Determinação de massa específica, massa específica aparente e absorção de água. Rio de Janeiro, 2009.

CAMPOS, H. F. Concreto de alta resistência utilizando pó de pedra como substituição parcial do cimento Portland: Estudo experimental. Dissertação (Mestrado em Engenharia de Construção Civil) - Universidade Federal do Paraná. Curitiba, 2015.

CASTRO, A. L.; PANDOLFELLI, V. C. Revisão: Conceitos de dispersão e empacotamento de partículas para a produção de concretos especiais aplicados na construção civil. Curitiba, v.55, out. 2009. 
CUCHIERATO, Gláucia. Caracterização tecnológica de resíduos da mineração de agregados da região metropolitana de São Paulo (RMSP), visando seu aproveitamento econômico. Dissertação de mestrado. Universidade de São Paulo. São Paulo, 2000.

DE LARRARD, F.; SEDRAN, T. Optimization of ultra-high-performance concrete by the use of a packing model. Cement Concrete Research, 1994.

DUARTE, J. B. Estudo da substituição de agregados miúdos naturais por pó de pedra em concreto de cimento portland. Dissertação de Mestrado. Universidade Federal do Rio Grande do Norte. 2013.

FUNK, J.E.; DINGER, D.R. Particle packing, part II: review of packing of polydisperse particle systems. In: Interceram, 1992.

JOHN, V. M.; AGOPYAN, V. Reciclagem de resíduos da construção. In: SEMINÁRIO RECICLAGEM DE RESÍDUOS DOMICILIARES. São Paulo, 2003.

MEHTA, Povindar Kumar; MONTEIRO, Paulo J.M. Concreto: estrutura, propriedades e materiais. São Paulo: Pini, 1994.

MENDES, K, da S. Viabilidade do emprego de finos de basalto em concreto compactado a rolo. Dissertação de mestrado. Escola Politécnica de São Paulo. São Paulo, 1999.

MENOSSI, R. T. Utilização do pó de pedra basáltico em substituição a areia natural do concreto. Tese de Doutorado. Unesp - Faculdade de Engenharia. São Paulo. 2004.

METHA P. K.; MONTEIRO P. J. M. Concreto: Microestrutura, Propriedades e Materiais. São Paulo: IBRACON, 2008.

MONSON, A. R.; MONGE, C. L.; GONÇALVES, J. O.; LENZ, L. A. Influência do Empacotamento da Estrutura Granular na Resistência à Compressão de Concretos Utilizados Para a Fabricação de Postes Duplo T. Revista Eletrônica Multidisciplinas FACEAR, v. 2, p. 1, 2016.

NEVILLE, A. M. Propriedades do concreto. $5^{a}$ edição, Editora Bookman, Porto Alegre, 2016.

OLIVEIRA, I. R.; STUDART, A. R.; PILEGGI, R. G.; PANDOLFELLI, V. C. Dispersão e empacotamento de partículas: princípios e aplicações em processamento cerâmico. São Paulo: Fazendo Arte Editorial, 2000.

PERA, J. State of the art report - use of waste materials in construction in Western Europe. In: WORKSHOP SOBRE RECICLAGEM E REUTILIZAÇÃO DE RESÍDUOS COMO MATERIAIS DE CONSTRUÇÃO, 1996, São Paulo. Anais. São Paulo: EPUSP/ANTAC, 1996. 
ROSSIGNOLO, J. A. Concreto leve estrutural: Produção, propriedades, microestrutura e aplicações. São Paulo: Pini, 2009.

ROSSIGNOLO, J.A. Concreto leve de alto desempenho modificado com SB para pré-fabricados esbeltos - dosagem, produção, propriedades e microestrutura. Universidade de São Paulo, São Carlos, 2003.

SANTOS, B. S.; NETA, D. S. R.; OLIVEIRA, N. K. A.; NASCIMENTO, R. F.; FIGUEIREDO, S. S.; BATISTA, L. S. Estudo da utilização do pó de pedra em substituição parcial a areia como agregado miúdo. Anais do $60^{\circ}$ Congresso Brasileiro Do Concreto, IBRACON, 2018.

SANTOS, T. F. Substituição da areia natural por areia de britagem de rochas basálticas para argamassas de assentamento. Centro Universitário Univates, Lajeado, 2017.

SILVA, P. D.; SILVA, E. J. A influência de pó de brita substituindo areia e cimento na argamassa com vista à produção de telhas. 2012.

SOARES, L.; FUJIMURA, F.; HENNIES, T.; SILVA, M. A. R. Change of natural sand by fine crushing material of granitic and gneissic rock quarries. In: INTERNACIONAL SYMPOSIUM ON MINE PLANNING AND EQUIPMENT SELECTION. São Paulo, 1996.

SOARES, L.; MENDES, K. da S. Aproveitamento de finos de pedreiras. In: SEMINÁRIO MARKETING \& TECNOLOGIA EXPO'99. São Paulo, 1999.

SOUZA, C. L. M.; AZEVEDO, E. S.; DIAS, F. L.; ANDRÉ, S. H.; ROCHA, S. B. UTILIZAÇÃO DO PÓ DE PEDRA EM SUBSTITUIÇÃO A AREIA NATURAL NA PRODUÇÃO DO CONCRETO. Trabalho de conclusão de curso. Faculdade Capixaba de Nova Venécia. Nova Venécia, 2016.

TERRA, L. E. M. Finos de pedreira para confecção de concreto estrutural - práticas recomendadas. In: SEMINÁRIO DESENVOLVIMENTO SUSTENTÁVEL E A RECICLAGEM NA CONSTRUÇÃO CIVIL: PRÁTICAS RECOMENDADAS. São Paulo, 2000.

TUTIKIAN, B. F.; ISAIA, G. C.; HELENE, P. Concreto: Ciência e Tecnologia. São Paulo, 2011. WATANABE, P.S. Concretos especiais - propriedades, materiais e aplicações. Universidade Estadual Paulista, São Paulo, Bauru, 2008.

Recebido em: 11/04/2019.

Aceito em: 07/06/2019. 